\title{
Correction to: Effectiveness and safety of intravenous valproate in agitation: a systematic review
}

\author{
Miriam Olivola ${ }^{1,2} \cdot$ Serena Civardi ${ }^{2} \cdot$ Stefano Damiani ${ }^{2} \cdot$ Nicolo Cipriani $^{3} \cdot$ Andrea Silva $^{2} \cdot$ Alberto Donadeo $^{2}$. \\ Pierluigi Politi ${ }^{1,2} \cdot$ Natascia Brondino ${ }^{1,2}$
}

Published online: 13 January 2022

○) Springer-Verlag GmbH Germany, part of Springer Nature 2022

\section{Correction to: Psychopharmacology \\ https://doi.org/10.1007/s00213-021-06009-0}

In the published article, the name of the corresponding author was incorrectly presented. The first name should be Miriam and the surname should be Olivola.

The original article has been corrected.

Publisher's note Springer Nature remains neutral with regard to jurisdictional claims in published maps and institutional affiliations.

The original article can be found online at https://doi.org/10.1007/ s00213-021-06009-0.

Miriam Olivola miriam_olivola@asst-pavia.it

1 ASST Pavia, Pavia, Italy

2 Department of Brain and Behavioral Sciences, University of Pavia, Pavia, Italy

3 Department of Neuroscience, Rehabilitation, Ophthalmology, Genetics, Maternal and Child Health (DINOGMI),

University of Genoa, Genova, Italy 